\title{
O LAZER DE INTERESSE FÍSICO/ESPORTIVO NO COTIDIANO INFANTIL E SUA INTERFACE COM A SAÚDE
}

Recebido em: 17/01/2011

Aceito em: 14/02/2012

\author{
Junior Vagner Pereira da Silva ${ }^{1}$ \\ Universidade Estadual de Santa Cruz \\ Ilhéus - BA - Brasil \\ Universidade Católica de Brasília \\ Brasília - DF - Brasil
}

RESUMO: A investigação objetivou analisar as atividades de lazer de crianças de 8 a 10 anos de uma escola pública em Campo Grande - MS. Especificamente buscou investigar os tipos de Atividades de Lazer Fisicamente Ativas (ALFA's) e os tipos de Atividades de Lazer Fisicamente Passivas (ALFP's); analisar o tempo destinado as ALFA's e as ALFP's; discutir as implicações do tipo de atividade de lazer à saúde e investigar o tipo de atividades no lazer de meninos e meninas. $O$ estudo foi do tipo descritivo/exploratório, com 30 crianças entre 8 e 10 anos, de ambos os sexos. Os resultados indicam que as crianças se envolveram por mais tempo com as ALFP's do que com as ALFA's, sendo as ALFP's mais frequentes entre as meninas e as ALFA's entre os meninos. Conclui-se que a inatividade física (gênero contemplativo) predomina entre as vivências de lazer das crianças avaliadas, sendo observada interferência do gênero (masculino/feminino) sobre as oportunidades e tipos de lazer.

PALAVRAS-CHAVE: Criança. Atividades de Lazer. Saúde.

\section{LEISURE OF PHYSICAL/SPORT'S INTEREST IN INFANT'S DAILY LIFE AND ITS INTERFACE WITH HEALTH}

ABSTRACT: The study focused on analyze the leisure activities in infant's daily routines. Specifically it aimed at analyzing the time devoted to active leisure physical activities (ALPA's) and passive leisure physical activities (PLPA's); to discuss the implications of the type of leisure activity to health and analyze the daily activities of children according to gender (male and female). The type of research was exploratory, with 30 children between 8 and 10 years, of both genders. The results indicate that children engaged longer with the AFPs than with the AFAS, being AFPs more frequent among girls and the AFAs among boys. It is concluded that physical inactivity (contemplative) predominates among leisure activities of the children evaluated, being observed interference of gender on opportunities and types of leisure.

\footnotetext{
${ }^{1}$ Doutorando em Educação Física pela Universidade Católica de Brasília, Bolsista CAPES/PROSUP; Docente Colegiado de Educação Física - Universidade Estadual de Santa Cruz - UESC.
} 
KEYWORDS: Child. Leisure Activities. Health.

\section{INTRODUÇÃO}

O lazer $^{2}$ configura-se como um campo de investigação multidisciplinar e envolve pesquisadores de diversas áreas de conhecimento, tais como Sociologia, Educação, Educação Física, Arquitetura e Urbanismo, História, Psicologia, Artes, Educação, dentre outras, podendo, ainda, essas áreas e sub-áreas de conhecimentos estarem relacionadas a um ou mais conteúdos culturais.

Desta forma, a multidisciplinaridade existente no lazer pode ser percebida através dos diferentes interesses que podem levar uma pessoa a se envolver com este tipo de ocupação do tempo disponível, interesses esses conceituados como conteúdos culturais. Embora diferenciados apenas pela predominância, logo podendo uma atividade de lazer ser permeada por mais de um interesse, Dumazedier (1980) defende que a procura pelo lazer pode estar vinculada a um dos cinco interesses culturais por ele apresentados - manual (caracterizado por atividades de ordem e necessidades psicológicas, realizada através de manipulação e consertos de objetos, pela criação ou transformação de matérias); intelectual (atividades com as quais se busca contato com o real ou um conhecimento objetivo, representado pelo domínio do real sobre o imaginário, físico e social); artístico (evidenciado pela predominância do imaginário sobre o real, buscando-se o contato com o fictício, com o estético, com o belo); social (representado pela necessidade de filiação a um grupo, concretizando-se pelas relações interpessoais e pela busca do contato face a face) e físico/esportivo (compreendido pela

\footnotetext{
${ }^{2}$ Entendido na perspectiva do tempo/atitude enquanto cultura, no seu sentido mais amplo, seja pela prática ou fruição, no tempo disponível, que tem como traço definidor o caráter "desinteressado" dessa vivencia, aonde não se busca outra recompensa se não além da satisfação provocada pela situação. (MARCELLINO, 2004, p. 28).
} 
busca de exercícios físicos e esportivos, assim como pelas atividades relacionadas à cultura física, tanto pela prática quanto pela assistência do espetáculo das atividades relacionadas ao esporte), sendo os interesses definidos em conformidade com a predominância.

Ainda, pode estar relacionada ao interesse turístico proposto por Camargo (1986). Vislumbrando a possibilidade de ampliação dos interesses culturais do lazer, o autor destaca a existência de um sexto interesse cultural, o turístico, que se caracterizaria pela busca do contato com paisagens, pela mudança de ritmo e estilo de vida, alterando a rotina cotidiana.

Embora a classificação proposta por Dumazedier (1980) e acrescentada por Camargo (1986) nos últimos anos seja a mais aceita, a criação de vários equipamentos eletrônicos, a proliferação da comunicação em rede - internet - e sua utilização nas oportunidades de lazer, tem feito com que autores defendam que as possibilidades de lazer também ocorram orientadas por um sétimo interesse, o virtual (SCHWARTZ, 2003).

Em decorrência dos grandes avanços tecnológicos ocorridos nas últimas décadas, principalmente os diversos meios de comunicação - jornal, livros, indústria da música, difusão televisiva e especialmente a conexão em rede - e com base nas inquietações contemporâneas, para Schwartz (2003), torna-se necessário um redimensionamento da proposta de Dumazedier (1980) e Camargo (1986), assim como uma reflexão da existência atual de um novo conteúdo cultural do lazer - $o$ virtual -, pois diante desses novos meios de comunicação, segundo a autora, várias são as possibilidades de informação advindas do mundo virtual, inclusive no que tange ao lazer, uma vez que se pode vivenciar tanto a contemplação por visualizar novos locais 
quanto se torna possível à participação em eventos, conhecer pessoas, aprender determinados dados culturais.

Percebe-se, com isso, que as possibilidades oferecidas pela internet, pelo computador e pela televisão ampliam as chances da população vivenciar os interesses culturais do lazer, haja vista que pessoas que jamais teriam condições financeiras para conhecer lugares longínquos, podem ter a oportunidade de, através da conexão em rede, conhecer pontos turísticos nacionais e internacionais, cidades e países diferentes; se comunicar e se relacionar com pessoas em países diferentes; assistir a filmes, shows e a jogos esportivos; apreciar obras de arte; ler livros e acessar informações; tudo isso via on-line . $^{3}$

A respeito da característica do lazer realizado pela população brasileira, Marcellino (2002) expõe que a ocupação do tempo disponível, em sua maioria, ocorre nos próprios locais de moradia, dentro de casa, com experiências contemplativas ${ }^{4}$, tendo o "assistir à televisão" como principal atividade, o que tem resultado na formação de um público cativo à televisão. Contudo, ao utilizar a moradia como principal local de lazer, outros estudos têm evidenciado que as atividades contemplativas não têm se limitado ao assistir televisão, pois elevados percentuais da população também têm destinado parte do seu tempo à internet e vídeo games, sendo essa realidade observada em estudos desenvolvidos no âmbito nacional com crianças (BARUKI et al., 2006; FIATES; AMBONI; TEIXEIRA, 2008; SILVA et al., 2009; SOUZA JUNIOR; VILELA JUNIOR, TOLOCKA, 2010), adolescentes - (SILVA; SILVA, 2008; CESCHINI et al.,

\footnotetext{
${ }^{3}$ Entendemos que os meios de comunicação de massa (televisão, internet e vídeo games) configuram-se como mecanismos de acesso aos seis interesses culturais do lazer propostos por Dumazedier (1980) e Camargo (1986) e não como um interesse em si. No entanto, com a crescente inserção de filmes em 3D e 7D no mercado cinematográfico, entendemos ser possível a materialização do interesse cultural virtual.

${ }^{4}$ Dumazedier (1980) postula que o lazer pode ser vivenciado sob três formas (gêneros) - contemplativo, prático e do conhecimento.
} 
2009; SILVA et al., 2009) e adultos (FLORINDO et al., 2009; MARTINS et al., 2009; DUCA et al., 2009) e em pesquisas realizadas em outros países com crianças portuguesas, de Bragança (CAMPOS; GOMES; OLIVEIRA, 2008), adolescentes americanos (BERRIGAN et al., 2006), finlandeses (TAMMELIN et al., 2007) e portugueses (TEIXEIRA e SEABRA et al., 2008) e adultos portugueses (CAMÕES; LOPES, 2008). Especificamente com crianças brasileiras, os estudos indicam que a maioria delas gasta de 2h50min (BARUKI et al., 2006) a 4h (FIATES; AMBONI; TEIXEIRA, 2008) por dia com esse tipo de lazer.

Embora do ponto de vista cultural a ocupação do tempo disponível com atividades de lazer contemplativas sejam tão importantes quanto às práticas, pois em si mesmo o lazer não é ativo ou passivo, estando essa condição relacionada à atitude tomada pelo indivíduo, ou seja, pelo seu nível de participação ${ }^{5}$ (DUMAZEDIER, 1980), sendo assim importante que a sociedade seja incentivada, iniciada e estimulada a vivenciar os seis interesses culturais do lazer, nos gêneros prático, contemplativo e do conhecimento e em níveis médio e superior, o que pode contribuir para um duplo processo educativo - educação para o lazer e pelo lazer (MARCELLINO, 2002), numa acepção fisiológica e de interface lazer-saúde, a prevalência das atividades de lazer contemplativas, classificadas no âmbito da saúde como ALFP's, podem trazer sérios problemas ao bem estar e à saúde da sociedade, haja vista que, de acordo com a Sociedade Brasileira de Cardiologia (SBC), em termos ideais à saúde, a inatividade recreacional com tv/dia deve ser inferior a $\mathrm{h} 2 \mathrm{~h} / \mathrm{d}$ (SBC, 2005), isto porque $\mathrm{o}$ sedentarismo pode desencadear sérios problemas à saúde, dentre eles a obesidade, que se configura num problema de saúde pública mundial (OLIVEIRA; FISBERG, 2003), e,

${ }^{5}$ Para Dumazedier (1980) o lazer pode ser vivenciado sob três níveis - conformista (consumo), crítico (criticidade) e crítico-criativo (criatividade). 
ainda, representa fator de risco à doenças degenerativas, risco a morbidades (ANDERSEN et al., 2006), doenças coronarianas, hipertensão, diabetes, depressão e outros agravos crônicos (GARRET et al., 2004).

Por outro lado, cabe ressaltar que o lazer de interesse físico/esportivo no gênero prático, ou seja, as ALFA's podem configurar-se como importantes oportunidades de promoção de hábitos saudáveis, bem estar e promoção da saúde, uma vez a prática de atividades físicas e percepções positivas sobre elas na infância favorecem a adoção de um estilo de vida fisicamente ativo na idade adulta (BLAIR et al., 1989; SBME, 1998).

Diante ao exposto, este estudo teve como objetivo analisar as atividades de lazer de crianças de 8 a 10 anos de uma escola pública em Campo Grande - MS. Especificamente buscou investigar os tipos de Atividades de Lazer Fisicamente Ativas (ALFA's) e os tipos de Atividades de Lazer Fisicamente Passivas (ALFP's); analisar o tempo destinado às ALFA's e as ALFP's; discutir as implicações do tipo de atividade de lazer à saúde e investigar o tipo de atividades no lazer de meninos e meninas.

\section{METODOLOGIA}

O estudo foi caracterizado como descritivo/exploratório. A pesquisa descritiva, segundo Gil (2010), tem como finalidade a descrição de determinadas características de uma população e a identificação de possíveis relações entre variáveis. Já a investigação exploratória, por sua vez, de acordo com Oliveira (2002), possibilita a descoberta de práticas que precisam ser modificadas e a elaboração de alternativas que possam substituí-las.

Considerando que experiências positivas em atividades físicas na infância favorecem sua ocorrência na idade adulta (BLAIR et al., 1989; SBME, 1998) e que crianças com idade inferior a 7 anos não apresentam conservação de tempo por estarem 
numa fase cognitiva pré-operatória (PIAGET, 1971), a amostra foi composta por 30 crianças, sendo 18 meninos e 12 meninas, entre 8 e 10 anos, matriculadas em uma escola pública de Campo Grande - MS. A seleção da amostra procedeu-se de forma casual para a escola e aleatória para as crianças, conforme indicações de Thomas e Nelson (2008).

As atividades do cotidiano infantil foram avaliadas utilizando como técnica de investigação a entrevista. Essa técnica de pesquisa consiste no encontro e conversação profissional entre duas pessoas - pesquisador e sujeitos da pesquisa -, a fim da obtenção de informações a respeito de um determinado assunto (MARCONI; LAKATOS, 2002). Quanto ao tipo da entrevista, optou-se por sua realização no formato padronizado/estruturado, que consiste em seguir um roteiro de perguntas previamente determinadas, aplicadas em conformidade com sua disposição no formulário, o que não permite que ao longo do estudo o pesquisador altere a ordem dos tópicos ou inclua outras questões (MARCONI; LAKATOS, 2002).

Como instrumento, a exemplo dos estudos realizados por Faria et al. (2010) e Souza Junior, Vilela Junior e Tolocka (2010), utilizou-se o Formulário de atividades de lazer para pré-púberes proposto por Silva, Marcellino e Tolocka (2004), adaptado aos objetivos deste estudo. Esse instrumento é composto por questões referentes ao envolvimento infantil com: deslocamento de casa para a escola e da escola para casa; atividades de lazer fisicamente ativas - ALFA's (atividades de lazer que exigem esforço físico, tais como: correr, saltar, pular, trepar, cair, arremessar, esportes, entre outras) e atividades de lazer fisicamente passivas - ALFP's (assistir à televisão, jogar vídeo games passivos e utilizar a internet/computador). Tal formulário é estruturado com questões fechadas referentes a atividades realizadas em dias úteis (terça-feira) e ao final 
de semana (domingo), com alternativas de respostas dadas em quantidades de horas. Sua aplicação se deu diretamente às crianças em local específico - sala da direção da escola -, atendidos individualmente, sendo o formulário preenchido por um único pesquisador e aplicado na quarta-feira.

A adoção de apenas dois dias da semana para análise das atividades de lazer, representando respectivamente semana (terça-feira) e final de semana (domingo), se deu em decorrência das características cognitivas descritas pela literatura (pensamento concreto) para indivíduos na faixa etária avaliada, condição cognitiva esta que por vezes resulta em menor habilidade do sujeito em recordar as atividades (PIAGET, 1971), sendo assim recomendado que a aplicação de instrumentos recordatários, como questionários e/ou formulários, sejam relacionados as atividades realizadas no mesmo dia ou dia anterior a sua aplicação (FARIAS JUNIOR; PIRES; LOPES, 2003).

Os dados deste estudo fazem parte de uma pesquisa mais ampla, desenvolvida no Mestrado em Educação Física na Universidade Metodista de Piracicaba (UNIMEP), que consistiu na análise do cotidiano infantil, crescimento físico e estágio das habilidades motoras básicas, o que justificou a limitação da amostra a 30 indivíduos, pois na ocasião do estudo o protocolo adotado para a análise dos estágios das habilidades motoras requeria várias etapas (filmagem, seleção das imagens, editoração do filme quadro a quadro e análise), restringindo, assim, uma amostragem maior.

Como critério de inclusão utilizou-se a idade (8 a 10 anos), a entrega do Termo de Consentimento Livre e Esclarecido assinado pelos pais e a participação em todas as etapas da pesquisa. O estudo seguiu as determinações do Conselho Nacional de Saúde, atendendo a Resolução CNS nº 196/96, sendo o mesmo aprovado pelo Comitê de Ética em Pesquisa da UNIMEP sob o protocolo n 045/04, de 24 de maio de 2004 e o Termo 
de Consentimento Livre e esclarecido assinado pelos pais e/ou responsáveis pelos menores.

No tratamento dos dados recorreu-se as análises estatísticas de média e frequência absoluta.

\section{RESULTADOS E DISCUSSÃO}

Em relação ao tempo destinado às atividades de lazer, as crianças se envolveram por mais tempo com as ALFP's do que com as ALFA's, apresentando um valor médio de 3:36h/d na semana e 3:06h/d no final de semana. Já as ALFA's apresentaram a média de $1: 50 \mathrm{~h} / \mathrm{d}$ na semana e $1: 33 \mathrm{~h} / \mathrm{d}$ no final de semana.

Conforme pode ser visualizado na TAB. 1, a análise de frequência, também indicou que na semana, as ALFP's figuraram como as atividades de lazer em que as crianças gastaram mais tempo, sendo que a maioria delas dedicavam mais de 4 horas a esse tipo de lazer, condição semelhante ocorrida no domingo.

TABELA 1

Análise de frequência absoluta do tempo gasto em ALFA's e ALFP's

\begin{tabular}{c|c|c|c|c}
\hline & \multicolumn{2}{|c|}{ Terça-feira } & \multicolumn{2}{c}{ Domingo } \\
\hline Quantidade de horas & ALFP's & ALFA's & ALFP's & ALFA's \\
\hline Até 1h & 1 & 19 & 4 & 20 \\
$2 \mathrm{~h}$ & 7 & 9 & 6 & 10 \\
$3 \mathrm{~h}$ & 2 & - & 4 & - \\
$>4 \mathrm{~h}$ & 20 & 2 & 16 & - \\
\hline
\end{tabular}

A predominância das atividades sedentárias nos momentos de lazer de crianças também tem sido evidenciada em diversos estudos desenvolvidos em âmbito nacional, 
sendo os resultados desta investigação próximos aos obtidos por Riveira et al. (2010), com crianças de Maceió (3.6h/d de tv) e superior aos evidenciados por Baruki et al. (2006) em Corumbá, MS (2:56h/a de televisão, vídeo games e computador) e Oliveira et al. (2010) em São Luis (2.66h/a de televisão, vídeo games e computador).

Percebe-se com isso, que alterações negativas, quando a perspectiva é a interface lazer/saúde, vêem ocorrendo no investimento do tempo infantil nas oportunidades de lazer, sendo o tempo de envolvimento com o lazer eletrônico superior aos recomendados como limites e ideais à saúde (SBC, 2005).

O tempo destinado as atividades eletrônicas e o elevado percentual de crianças que tem usufruído deste tipo de lazer por longo período, deve ser visto com preocupação pelos pais, profissionais da saúde e poder público, pois o sedentarismo tem se constituído num dos principais responsáveis pelo sobrepeso corporal e obesidade infantil no Brasil (GIUGLIANO; CARNEIRO, 2004; OLIVEIRA et al., 2010; RIVERA et al., 2010), na Suíça (STETTLER; SINGER; SUTER, 2004) e em três regiões européias (EKELUND et al., 2006). Ainda devemos estar cientes de que crianças obesas, quando comparadas às eutróficas, têm apresentado 3,6 vezes mais risco de pressão arterial sistólica aumentada; 2,7 vezes para pressão arterial diastólica aumentada e 3,8 vezes mais chances de ter colesterol total aumentado, sendo que $1 / 3$ das crianças com colesterol total elevado tem um risco moderado e grave de desenvolver doença aterosclerótica quando atingir a idade adulta (RIBEIRO et al., 2006). Ademais, usufruir o lazer eletrônico (televisão, vídeo games e computador) por tempo prolongado consiste num fator de risco à doenças cardiovasculares (MOLINA et al., 2010)

Analisando as atividades cotidianas de acordo com o sexo, verificou-se que, na semana, as meninas FIG. 1 dedicaram mais tempo às ALFP's que os meninos FIG. 2; o 
inverso ocorrendo no fim de semana. Ainda, tanto na semana (terça-feira) quanto no fim de semana (domingo), os meninos se envolveram por mais tempo que as meninas com as ALFA's.

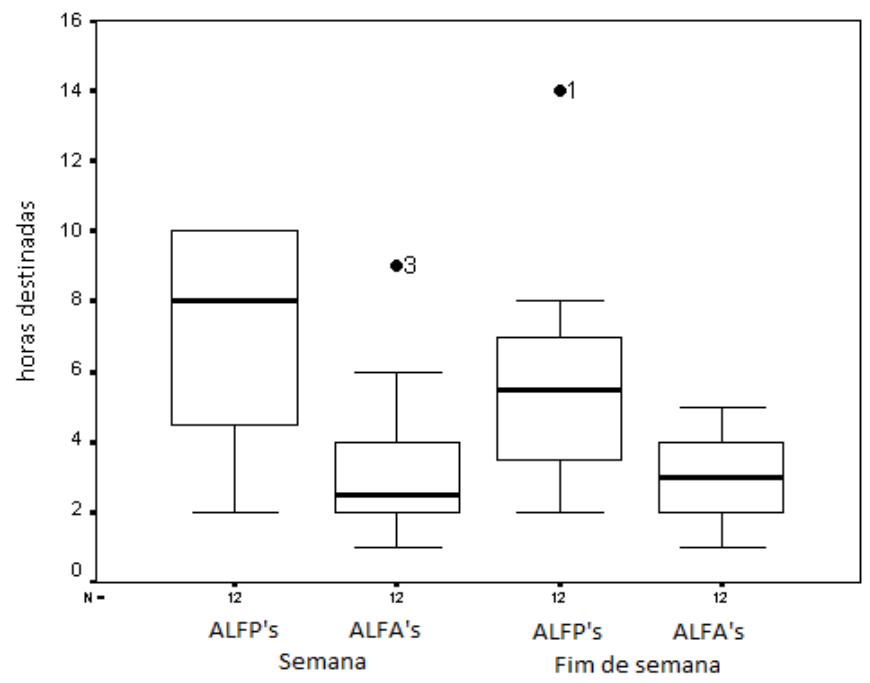

FIGURA 1- Boxplot das atividades cotidianas realizadas pelas meninas

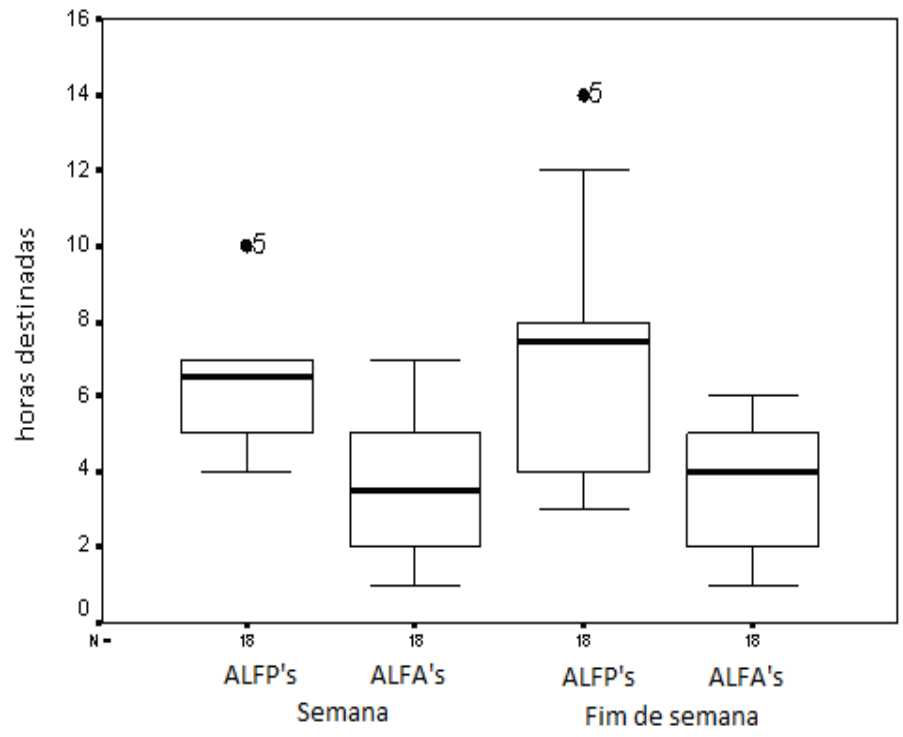

FIGURA 2. Boxplot das atividades cotidianas realizadas pelos meninos O predomínio do envolvimento das meninas com ALFP's e a prática de ALFA's superior entre os meninos, converge com resultados obtidos em investigações realizadas 
em São Paulo, SP (JENOVESI et al., 2003), João Pessoa, PB (SILVA; LOPES; SILVA, 2007), Curitiba, PR (SILVA et al., 2010).

Em parte, isso pode estar ocorrendo devido à existência de uma estrutura sociocultural que, desde o nascimento, exerce influência sobre as ações infantis, levando as crianças a seguirem normas e valores determinados previamente como adequados a cada sexo, inclusive nos jogos/brincadeiras (POMAR; CARLOS NETO, 2003), o que do ponto de vista da adoção de um estilo de vida fisicamente ativo, pode resultar em sérios prejuízos às meninas, pois enquanto aos meninos são oportunizadas atividades mais livres e vigorosas - como soltar pipas, jogar bola na rua, escalar muros, andar de bicicletas, entre outras -, as meninas são impedidas de praticarem tais brincadeiras (RANGEL; DARIDO, 2005).

Refletindo sobre as oportunidades de lazer, Marcellino (2002) expõe que em decorrência de normas e valores socioculturais, existe uma diferença significativa no uso do tempo disponível entre homens e mulheres, tanto na fase adulta quanto na infância: se na idade adulta as restrições ocorrem devido à dupla jornada de trabalho, já que grande parte das mulheres além de exercer funções profissionais acumula ainda a função de dona de casa e mãe, na infância, as meninas têm seu tempo de lazer diminuído por serem inseridas, desde cedo, em funções tidas como "de mulheres", tais como cuidar de casa e/ou dos irmãos mais novos.

As diferenças entre os sexos no cotidiano infantil também foi encontrada em estudo desenvolvido junto a crianças residentes em João Pessoa, PB. Na ocasião, Silva, Lopes e Silva (2007) observaram que enquanto um terço dos meninos afirmou jogar futebol, percentual similar das meninas informou cuidar das tarefas domésticas. Pesquisa desenvolvida por Burgos e Gaya (2001), com escolares da $1^{\mathrm{a}}$ a $4^{\mathrm{a}}$ séries, 
residentes em Santa Cruz do Sul - RS, verificou dados semelhantes, sendo que ajudar na tarefa doméstica e cuidar dos irmãos mais novos foram atividades predominantes entre as meninas.

Fruto de uma concepção social construída historicamente, os estereótipos de gênero relacionados às práticas corporais partem da concepção de que "homens são fortes" e "mulheres são frágeis" (SIMÕES; CONCEIÇÃO; NERI, 2004), levando a uma imposição social de atividades do tipo competitivas e agressivas aos meninos e delicadas às meninas (SAMPAIO, 2002), agindo de forma negativa na inserção feminina nas competições esportivas, como o cenário Olímpico (GOELLNER, 2005) e no tipo de exercícios físicos e esportes recomendados para homens e mulheres em sua inserção no âmbito escolar (ADELMAN, 2003), se estendendo até os dias de hoje no jogo infantil, o que tem contribuído para que atividades que envolvem maior manifestação de força (lutas e futebol) sejam entendidas como próprias de meninos e aquelas que exigem mais agilidade e menos força (pular corda/elástico) como de meninas (GOMES; MARQUES; NUNES, 2005).

Percebe-se, consequentemente, que os valores e normas estabelecidas pela sociedade como apropriadas a meninos e meninas fazem com que as meninas sejam triplamente prejudicadas, pois, além de terem menos oportunidades de jogos/brincadeiras que envolvem maior esforço físico (JENOVESI et al., 2003; SILVA; LOPES; SILVA, 2007; SILVA et al., 2010), as poucas oportunidades que tem, as atividades configuram como ações estéticas e de pouco vigor físico, o que, além de resultar em condições desiguais de emancipação humana, também pode estar contribuindo para maior predominância de problemas de saúde relacionados ao sedentarismo, como a obesidade, uma vez que estudos têm constatado que os 
percentuais de inatividade física (FIATES; AMBONI; TEIXEIRA, 2008) e obesidade (BARUKI et al., 2006; SILVA et al., 2008) são mais elevados entre meninas.

\section{CONSIDERAÇÕES FINAIS}

Observa-se que, assim como vem ocorrendo com adultos e adolescentes, a maioria das crianças avaliadas tem se envolvido por mais tempo com ALFP's nas atividades de lazer, o que indica, a exemplo de dados disponíveis na literatura, tendência ao sedentarismo infantil.

Quando analisado por gênero (masculino/feminino), as ALFA's foram mais frequentes entre as meninas e as ALFA's entre os meninos, tanto durante a semana quanto no fim de semana, o que sugere a ação do gênero (masculino/feminino) como barreira às oportunidades de lazer e variável influenciadora na inatividade física.

Evidencia, portanto, a urgência da criação de mecanismos de prevenção e intervenção em relação ao baixo envolvimento infantil com ALFA's, haja vista que as oportunidades de jogos motores, além de configurarem-se numa importante ação para o bem estar, prevenção de doenças, manutenção da saúde e criação de hábitos saudáveis relacionados à prática de atividades físicas, também se manifesta como ocasião essencial para que interações sociais ocorram, favorecendo descobertas sobre si, sobre o outro e sobre o mundo no qual está inserido, conforme exposto por Rojas (2007) e evidenciado em estudos desenvolvidos por Tolocka et al. (2009), Tolocka e Brolo (2010) e Faria et al. (2010), após período de intervenção com a aplicação de jogos junto a crianças.

A fim de ampliar as oportunidades de lazer de interesse físico/esportivo de gênero prático às crianças avaliadas entendemos ser oportuna: a ampliação do número 
de aulas de Educação Física semanal; a criação de projetos extra-curriculares com ênfase à atividade física e à saúde; a utilização da escola como equipamento nãoespecífico do lazer aos finais de semanas, dentre outras ações.

Por fim, diante das limitações do tamanho da amostra e dos diferentes fatores que podem atuar como barreiras ao lazer, sobretudo aos de interesse físico/esportivo, torna-se importante que novos estudos sejam realizados com o intuito de investigar a relação entre o tipo de atividade de lazer cotidiano (ALFA's e ALFP's) e outras variáveis, como a idade, o local de moradia, o nível sócio-econômico, entre outros. Fazse necessário, também, que em futuras investigações sejam analisadas outras questões, como os espaços/locais que as crianças dispõem e utilizam para "o brincar" e as ações que têm sido implementadas pelo poder público a fim de amenizar as barreiras ao lazer e ampliar as oportunidades de jogo na infância, pois muitas crianças têm o jogo limitado pelos pais ao espaço da casa ou quintal, conforme evidenciaram estudos realizados por Silva e Nunes (2008) e Souza Junior, Vilela Junior e Tolocka (2010),

\section{REFERÊNCIAS}

ADELMAN, Miriam. Mulheres atletas: re-significações da corporalidade feminina. Revista Estudos Feministas, v. 11, n. 2, p. 445-465, julho/dez. 2003.

ANDERSEN, L. B. et al. Physical activity and clustered cardiovascular risk in children: a crosssectional study (The European Youth Heart Study). Lancet, v. 368, n. 9532, p. 299-304, 2006.

BARUKI, S. B. S. et al. Associação entre estado nutricional e atividade física em escolares da Rede Municipal de Ensino em Corumbá-MS. Revista Brasileira de Medicina do Esporte, São Paulo, v. 12, n. 2, p. 90-94, mar.-abr. 2006. Disponível em: http://www.scielo.br/pdf/rbme/v12n2/v12n2a07.pdf. Acesso em: 17 out. 2010.

BERRIGAN, D. et al. Active transportation increases adherence to activity recommendations. Am. J. Prev. Med., v. 31, p. 210-216, 2006. 
BLAIR, S. et al. Exercise and finess in childhood: implications for a lifetime of health. In: GISOLFI, C. V.; LAM, D. R. (Org.). Perpectives in exercise science and sports medicine. 2 ed. Indianapólis: Benchmark, 1989. p. 401-430.

BURGOS, M. S.; GAYA, A. C. O lazer e as atividades lúdico-desportivas qualificados pelos hábitos de vida: uma resposta do contexto sociocultural. Cinergis, Santa Cruz do Sul, v. 2, n. 1, p. 115-141, 2001.

CAMARGO, L. O. de L. O que é lazer. São Paulo: Brasiliense, 1986.

CAMÕES, M.; LOPES, C. Fatores associados à atividade física na população portuguesa. Revista Saúde Pública, v. 42, n. 2, p. 208-216, 2008. Disponível em: http://www.scielo.br/pdf/rsp/v42n2/6378.pdf. Acesso em: 01 jan. 2011.

CAMPOS, L. F.; GOMES, J. M.; OLIVEIRA, J. C. Obesidade infantil, actividade física e sedentarismo em crianças do $1^{\circ}$ ciclo do ensino básico da cidade de Bragança (6 a 9 anos). Motricidade, v. 4, n. 3, p. 17-24, set. 2008. Disponível em: http://www.scielo.oces.mctes.pt/pdf/mot/v4n3/v4n3a04.pdf. Acesso em: 18 dez. 2010.

CESCHINI F. L. et al. Prevalence of physical inactivity and associated factors among high school students from state's public schools. Jornal de Pediatria, Rio Janeiro, v. 85, n. 4, p. 301-306, 2009.

DUCA, G. F. D. et al. Associação entre nível econômico e inatividade física em diferentes domínios. Revista Brasileira de Atividade Física \& Saúde, v. 14, n. 2, p. 123-131, 2009. Disponível em: http://www.sbafs.org.br/ artigos/240.pdf. Acesso em: 02 jan. 2011.

DUMAZEDIER, J. Valores e conteúdos culturais do lazer. São Paulo: SESC, 1980.

EKELUND, U. et al. TV viewing and physical activity are independently associated with metabolic risk in children: The European Youth Study. PLos Medicine, v. 3, n. 12, p. 1949-1956, 2006.

FARIA, M. C. M. et al. Atividades motoras cotidianas e suas influências no desenvolvimento de pré-escolares. Revista Movimento, Porto Alegre, v. 16, n. 1, p. 18, 2010. Disponível em: http://seer.ufrgs.br/Movimento/article/view/4991/7520. Acesso em: 02 jan. 2011.

FARIAS JUNIOR, J. D.; PIRES, M. C.; LOPES, A. S. Medidas de atividades físicas em crianças: idade escolar (7 a 13 anos). In: BARROS, M. V. G.; NAHAS, M. V. (Org.). Medidas da atividade física: Teoria e aplicação em diversos grupos populacionais. Londrina: Midiograf, 2003. p. 59-70.

FIATES, G. M. R.; AMBONI, R. D. M. C.; TEIXEIRA, E. Comportamento consumidor, hábitos alimentares e consumo de televisão por escolares de Florianópolis. 
Revista de Nutrição, Campinas, v. 21, n. 1, p. 105-114, jan.-fev. 2008. Disponível em: http://www.scielo.br/pdf/rn/v21n1/a11v21n1.pdf. Acesso em: 29 nov. 2009.

FLORINDO, A. A. F. et al. Prática de atividades físicas e fatores associados em adultos, Brasil, 2006. Revista Saúde Pública, v. 43, Supl. 2, p. 65-73, 2009. Disponível em: http://www.scielo.br/pdf/rsp/v43s2/ao797.pdf. Acesso em: 03 jan. 2011.

GARREtT, N. A. et al. Physical inactivity direct cost to a health plan. Am. J. Prev. Med., v. 27, n. 4, p. 304-309, 2004.

GIL, Antonio Carlos. Métodos e técnicas de pesquisa social. 6. ed. São Paulo: Atlas, 2010.

GIUGLIANO, R.; CARNEIRO, E. Fatores associados à obesidade em escolares. Jornal de Pediatria, Rio de Janeiro, v. 80, n. 1, p. 17-22, jan.-fev. 2004. Disponível em: http://www.scielo.br/pdf/jped/v80n1/v80n1a05.pdf. Acesso em: 03 out. 2009.

GOELLNER, S. V. Mulher e esporte no Brasil: entre incentivos e interdições elas fazem história. Pensar a prática, v. 8, n. 1, p. 85-100, janeiro/jun. 2005.

GOMES, P. B.; MARQUES, A. I.; NUNES, M. Estereótipos femininos e masculinos de jogos do recreio escolar: estudo em crianças de diferentes contextos culturais. In: GOMES, P. B.; CRUZ, I. (Org.). Mulheres e desporto: agir para a mudança. Lisboa: Associação Portuguesa a mulher e o desporto, 2005. p. 36.75.

JEVONESI, J. F. et al. Perfil de atividade física em escolares da rede pública de diferentes estados nutricionais. Revista Brasileira de Ciência e Movimento, Taguatinga, v. 11, n. 4, p. 57-62, out.-dez. 2003. Disponível em: http://portalrevistas.ucb.br/index.php/RBCM/article/viewFile/527/551. Acesso em: 30 nov. 2009.

MARCELlinO, N. C. Estudos do lazer: uma introdução. São Paulo: Autores Associados, 2002.

Pedagogia da animação. 6. ed. Campinas: Papirus, 2004.

MARCONI, M. de A.; LAKATOS, E. M. Técnicas de pesquisa: planejamento e execução de pesquisas, amostragens e técnicas de pesquisas, elaboração, análise e interpretação de dados. 5. ed. São Paulo: Atlas, 2002.

MARTINS, T. G. et al. . Inatividade física no lazer de adultos e fatores associados. Revista Saúde Pública, v. 43, n. 5, p. 814-824, 2009. Disponível em: http://www.scielo.br/pdf/rsp/2009nahead/553.pdf. Acesso em: 03 jan. 2011.

MOLINA, M. D. C. B. et al. Fatores de risco cardiovascular em crianças de 7 a 10 anos de área urbana, Vitória, Espírito Santo, Brasil. Cad. Saúde Pública, v. 26, n. 5, p. 909 917, 2010.

OLIVEIRA, C. L. de; FISBERG, M. Obesidade na infância e adolescência: uma verdadeira epidemia. Arquivo Brasileiro de Endocrinologia e Metabolismo, v. 47, n. 
2, p. 107-108, 2003. Disponível em: http://www.abeso.org.br/pdf/set/Ob\%20infancia\%20\%20e\%20adolescencia\%20epidem. pdf. Acesso em: 16 nov. 2010.

OLIVEIRA, S. L. Tratado de metodologia científica. 2. ed. São Paulo, SP: Pioneira, 2002.

OLIVEIRA, T. C. de et al. Atividade física e sedentarismo em escolares da rede pública e privada de ensino em São Luís. Rev. Saúde Pública, v. 44, n. 6, p. 996-1004, 2010.

PIAGET, J. A formação do símbolo na criança. São Paulo: Zahar, 1971.

POMAR, C.; CARLOS NETO. Percepção da apropriação e do desempenho motor de gênero em actividades lúdico-motoras. In: CARLOS NETO (Org). Jogo \& desenvolvimento da criança. Cruz Quebrada: FMH, 2003. p. 178-205.

RANGEL, I. C. A; DARIDO, S. C. Jogos e brincadeiras. In: DARIDO, S. C.; RANGEL I. C. A. (Orgs). Educação Física na escola: implicações para a prática pedagógica. Rio de Janeiro: Guanabara Koogan, 2005. p. 155-175.

RIBEIRO, R. Q. C. et al. Fatores adicionais de risco cardiovascular associados ao excesso de peso em crianças e adolescentes. O estudo do coração de Belo Horizonte. Arquivos Brasileiros de Cardiologia, Rio de Janeiro, v. 86, n. 6, p. 408-418, 2006. Disponível em: http://www.scielo.br/pdf/abc/v86n6/29873.pdf. Acesso em: 17 nov. 20.

RIVERA, I. R. et al. Atividade Física, Horas de Assistência à TV e Composição Corporal em Crianças e Adolescentes. Arq. Bras. Cardiol., v. 95, n. 2, p. 159-165, 2010.

ROJAS, J. Jogos, brinquedos e brincadeiras: a linguagem lúdica formativa na cultura da criança. Campo Grande: UFMS, 2007.

SAMPAIO, T. M. V. Avançar sobre Possibilidades: horizontes de uma reflexão ecoepistêmica para redimensionar o debate sobre os esportes. In: MOREIRA, W. W.; SIMÕES, R. (Org.). Esporte como fator de qualidade de vida. Piracicaba: Unimep, 2002. p. 85-99.

SBC. Sociedade Brasileira de Cardiologia. I Diretrizes de prevenção da aterosclerose na infância e adolescência. Arquivos Brasileiros de Cardiologia, Rio de Janeiro, v. 85, Supp 6, p. 3-36, dez. 2005. Disponível em: http://www.scielo.br/pdf/abc/v85s6/v85s6a01.pdf. Acesso em: 03 dez. 2009.

SBME - Sociedade Brasileira de Medicina do Esporte. Atividade física e saúde na infância e adolescência. Rev. Bras. Med. Esporte, v. 4, n. 4, p. 107-109, 1998.

SCHWARTZ, G. M. O conteúdo virtual do lazer: contemporizando Dumazedier.. Licere, Belo Horizonte, v. 6, n. 2, p. 23-31, 2003.

SILVA, A. J. et al. A prevalência do excesso de peso e da obesidade entre crianças portuguesas. Fitness \& Performance Journal, Rio Janeiro, v. 7, v. 5, p. 301-305, 2008. 
Disponível em: http://www.fpjournal.org.br/painel/arquivos/11473_Prevalencia_de_excesso_de_peso_Rev5_2008_Portugues.pdf. Acesso em: 04 jan. 2011.

SILVA, D. A. S. et al. Nível de atividade física e comportamento sedentário em escolares. Revista Brasileira Cineantropometria Desempenho Humano, Florianópolis, v. 11, n. 3, p. 299-306, 2009. Disponível em: http://www.rbcdh.ufsc.br/DownloadArtigo.do?artigo=510. Acesso em: 15 dez. 2010.

SILVA, D. A. S.; SILVA, R. J. dos S. Padrão de atividade física no lazer e fatores associados em estudantes de Aracaju-SE. Revista Brasileira de Atividade Física \& Saúde, v. 13, n. 2, p. 94-101, 2008. Disponível em: http://www.sbafs.org.br/ artigos/68.pdf. Acesso em: 20 dez. 2010.

SILVA, J. V. P.; MARCELLINO, N. C.; TOLOCKA, R. E. Formulário de atividades de lazer para pré-púberes. In: ENCONTRO NACIONAL DE RECREAÇÃO E LAZER, 16., 2004, Salvador. Anais... Salvador: UFBA; 2004. v. 1, p. 511-518.

; NUNEZ, P. R. M. A cidade, a criança e o limite geográfico para os jogos/brincadeiras. Licere, Belo Horizonte, v. 11, n. 3, p. 1-14, 2008. Disponível em: http://www.anima.eefd.ufrj.br/licere/pdf/licereV11N03_a3.pdf. Acesso em: 13 nov. 2009.

SILVA, K. S.; LOPES, A. S.; SILVA, F. M. Atividade física no deslocamento à escola e no tempo livre em crianças e adolescentes da cidade de João Pessoa, PB, Brasil. Revista Brasileira de Ciência e Movimento, Taguatinga, v. 15, n. 3, p. 61-70, 2007. Disponível em: http://portalrevistas.ucb.br/index.php/RBCM/article/viewFile/761/764. Acesso em: 30 dez. 2009.

SILVA, M. P. et al. Comportamento sedentário relacionado ao sobrepeso e à obesidade em crianças e adolescentes. Pensar a Prática, Goiânia, v. 13, n. 2, p. 1-15, 2010. Disponível em: http://www.revistas.ufg.br/index.php/fef/article/view/6709. Acesso em: 14 jul. 2011.

SIMÕES, A. C.; CONCEIÇÃO, P. F. M.; NERY, M. A. da C. Mulher, Esporte, Sexo e Hipocrisia. In: SIMÕES, A. C.; KNIJNIK, J. D. (Orgs.). O mundo psicossocial da mulher no esporte: comportamento, gênero, desempenho. São Paulo: Aleph, 2004. p. 61-86.

SOUZA JUNIOR, J. G. de; VILELA JÚNIOR, G. de B.; TOLOCKA, R. E. Mudanças ocorridas na cidade de Uberaba - MS e suas possíveis influências no lazer infantil. Licere, Belo Horizonte, v.13, n.3, p. 1-21, set. 2010. Disponível em: http://www.anima.eefd.ufrj.br/licere/pdf/licereV13N03 a5.pdf. Acesso em: $21 \mathrm{dez}$. 2010.

STETTLER, N.; SINGER, T. M.; SUTER, P. M. Electronic games and environmental factors associated with childhood obesity in Switzerland. Obes. Res., v. 12, v. 6, p. 896903, 2004. 
TAMMELIN, T. et al. Physical activity and sedentary behaviors among Finnish youth. Med. Sci. Sports Exerc., v. 39, p. 1067-1074, 2007.

TEIXEIRA E SEABRA, A. F. et al. Age and sex differences in physical activity of Portuguese adolescents. Med. Sci. Sports Exerc., v. 40, p. 65-70, 2008.

THOMAS, J. R.; NELSON, J. K. Métodos de pesquisa em atividade física. Porto Alegre: ArtMed, 2008.

TOLOCKA, R. E.; BROLlO, A. L. Atividades físicas em instituições de ensino infantil: uma abordagem bioecológica. Revista Brasileira de Cineantropometria e Desempenho Humano, Florianópolis, v. 12, n. 2, p. 140-147, 2010. Disponível em: http://www.periodicos.ufsc.br/index.php/rbcdh/article/view/9303/11593. Acesso em: 15 nov. 2010.

et al. Como brincar pode auxiliar no desenvolvimento de crianças préescolares. Licere, Belo Horizonte, v. 12, n. 1, p. 1-10, 2009. Disponível em: http://www.anima.eefd.ufrj.br/licere/pdf/licereV12N01_a5.pdf. Acesso em: $18 \mathrm{dez}$. 2010.

\section{Endereço do Autor:}

Junior Vagner Pereira da Silva

Universidade Estadual de Santa Cruz - UESC

Departamento de Ciências da Saúde -

Campus Soane Nazaré de Andrade, Km 16 - Rodovia Ilhéus-Itabuna

45662-900 - Ilhéus - BA

Endereço Eletrônico: jr_lazer@yahoo.com.br 